\title{
Agriculture Waste for Sustainable Living in Rural Communities
}

\author{
Salah Arafa* \\ Professor, American University in Cairo, Egypt \\ *Corresponding Author: Salah Arafa, Professor, American University in Cairo, Egypt.
}

Received: July 19, 2019; Published: July 29, 2019

DOI: 10.31080/ASAG.2019.03.0591

Any material which cannot be used in the form in which it is produced and/or needed is called a "Waste" and has lost its value. But if it is left and thrown around, it can cause harm and poses a serious threats to the normal healthy life of plants, animals and human beings living in the community. Collective actions are needed to achieve sustainable living and community development by appropriate participatory management of water, Food, Waste, Energy in the different communities and regions of the world.

The environmental pollution phenomenon is considered as one of the most serious problems facing agriculture communities and represents a big challenge to the system of life. The most important reason of such environmental pollution is the lack of adequate awareness, education, training and policies that must be followed and well transferred to the end users in rural areas for a healthy and safe disposal of wastes in all its forms.

The scope of our study has been the identification of the available biomass resources and the assessment of their potential. In many countries of our world, the majority of the populations are living in the rural area and they can only maintain its rate of growth if the energy security is ensured. The rural sector cannot be only dependent on the conventional sources of energy.

There are several renewable sources of energy that can not only fulfil the rural energy needs but also would be a step towards its sustainable development. Rural agricultural waste might be an option for potential energy source and other valuable product that can enhance the standard of living of rural people. There exist today some feasible technologies that may be the route to convert rural waste to clean energy in addition with environmental and economic benefits.

All types of biomass waste have heat values greater than some of the well-known biomass-fuels and fall within the limit for the production of steam in electricity generation. As a result of this, it is envisaged that industries that use their waste biomass for energy would simultaneously solve a waste disposal problem and save money on their energy needs.

Many researchers and scientific conferences promote the efficient usage of natural resources for production of renewable energy by rural agricultural communities in order to ensure food safety and security; they also promote the usage of sustainable energy for various farm activities as well as to conserve water resources and environment to serve the interests of governments, private sector and the public as a whole. There is generally a strong commitment and active leadership in promoting education, research and innovation on renewable energy for sustainable community development.

The following figures show (1) The recycling of Agriculture wastes and (2) The innovative approache used in Basaisa Village, Al-Sharkiya Governorate in Egypt on how to transfer knowledge from where it exists to where it is needed (www.google.com/Basaisa). 


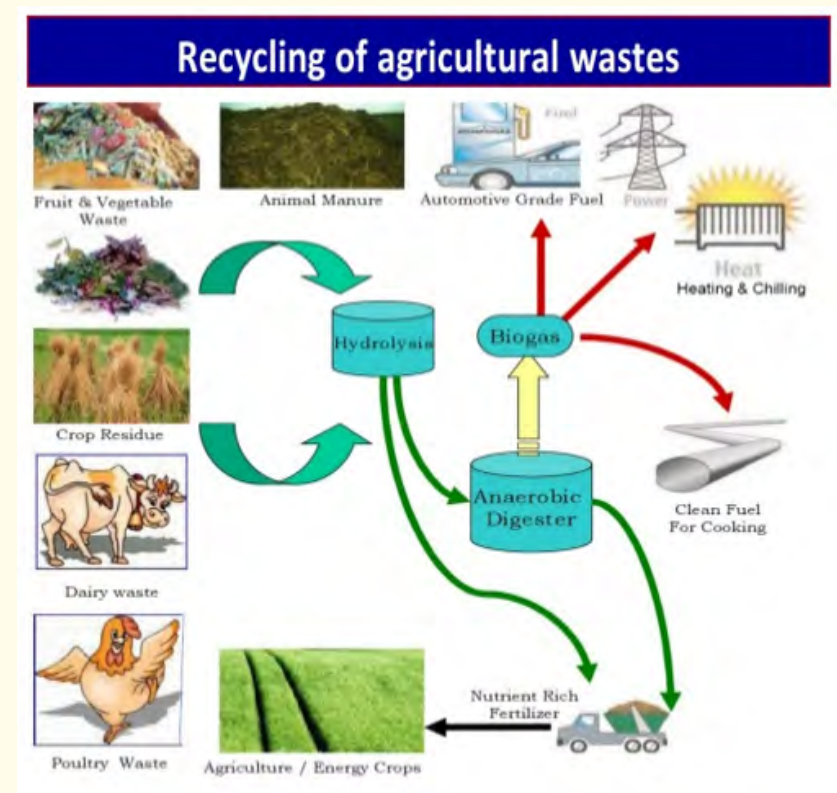

Figure 1

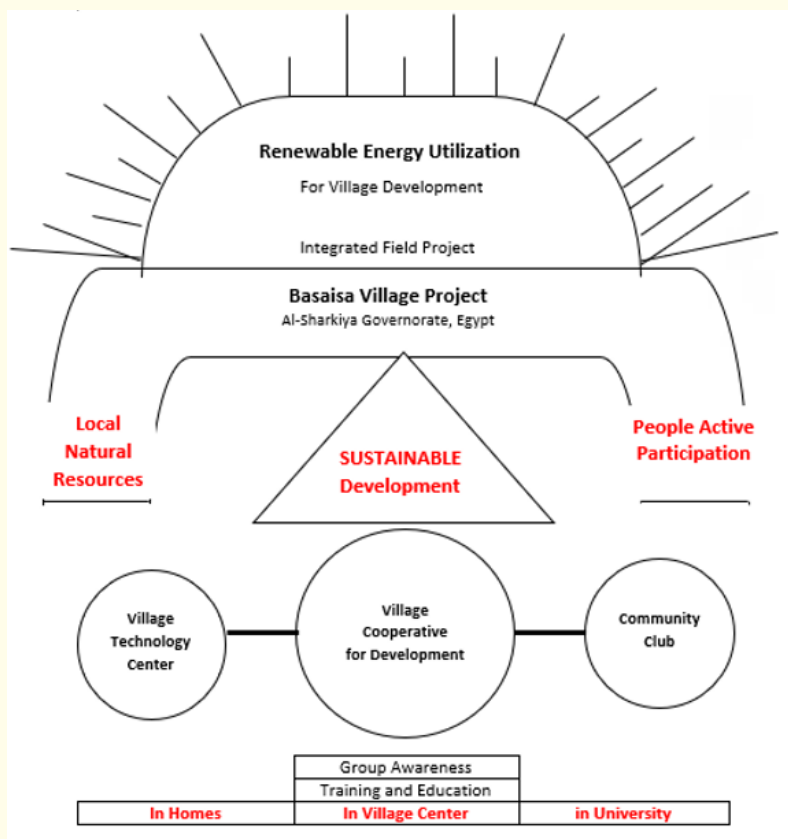

Figure 2

Volume 3 Issue 8 August 2019

(c) All rights are reserved by Salah Arafa. 